\title{
SISTEM INFORMASI ABSENSI MENGGUNAKAN FOTO SELFIE DAN GEOTAGGING
}

\author{
Berlian Fajar Prayogo', Rangga Sanjaya ${ }^{2}$ \\ 1 Universitas Adhirajasa Reswara Sanjaya \\ e-mail: kakberlian@gmail.com \\ ${ }^{2}$ Universitas Adhirajasa Reswara Sanjaya \\ e-mail: rangga@ars.ac.id
}

\begin{abstract}
Abstrak
Sistem informasi absensi merupakan suatu pendekatan strategis terhadap peningkatan kinerja suatu perusahaan. Absensi pegawai dapat dicatat, diolah dan dipresentasikan didalam suatu sistem informasi absensi. Banyak perusahaan yang menggunakan sistem absensi metode tradisional seperti mesin ceklok, fingerprint atau menggunakan media kertas yang memiliki berbagai keterbatasan dan kelemahan seperti membuat seorang pegawai yang ditugaskan diluar perusahaan harus datang ke kantor terlebih dahulu untuk melakukan absensi. Hal ini memungkinkan seorang pegawai tidak melakukan absensi dikarnakan memerlukan waktu lebih dalam melakukan absensi ke kantor. Untuk itu peneliti mencoba membuat aplikasi absensi selfie dan geotagging berbasis android yang menggunakan metode waterfall sebagai pengembangan sistem. Dengan adanya aplikasi yang dibuat maka dapat mempermudah pegawai dalam melakukan absensi dengan cara foto selfie dilokasi bertugas sehingga pegawai tidak perlu datang ke kantor untuk melakukan absensi yang akan memakan waktu dan jarak tempuh. Dan perusahaan dapat memonitoring pegawinya yang bertugas diluar perusahaaan.
\end{abstract}

Kata Kunci: Absensi; Android; Foto Selfie; Geotagging; Waterfall

\begin{abstract}
The attendance information system is a strategic approach to improving the performance of a company. Employee attendance can be recorded, processed and presented in an attendance information system. Many companies use attendance systems with traditional methods such as check machines, fingerprints or using paper media which have various limitations and weaknesses such as making an employee assigned outside the company have to come to the office first to do attendance. This allows an employee not to do attendance because it requires more time to attend to the office. For this reason, the researcher tries to make an android-based selfie and geotagging attendance application that uses the waterfall method as a system development. With the application made, it can make it easier for employees to take attendance by taking selfies at the location of duty so that employees do not have to come to the office to do attendance which will take time and mileage. And the company can monitor its employees who work outside the company.
\end{abstract}

Keywords: Attendance; Android; Selfie Photo; Geotagging; Waterfall

\section{Pendahuluan}

Manajemen Sumber Daya Manusia (SDM) atau Human Resource Management (HRM) merupakan serangkaian proses perencanaan hingga pengembangan dalam menangani hal-hal yang berkaitan dengan Sumber Daya Manusia (SDM) pada perusahaan secara lebih optimal sehingga tujuan dari perusahaan dapat tercapai
(Wardhani \& Aziz, 2018). Sumber daya manusia (SDM) berperanan begitu cukup penting dalam kemajuan suatu perusahaan. Berbagai kegiatan dan fungsi yang dibutuhkan dalam pengelolaan SDM salah satunya mengenai manajemen pengelolaan data absensi pegawai. Pada dasarnya sistem informasi absensi digunakan sebagai salah satu tolak ukur metode pengembangan pegawai, jika dalam mengelola absensi 
pegawai setelah mengikuti pengembangan menurun, maka metode pengembangan yang diterapkan berjalan dengan baik, sebaliknya jika absensi pegawai tetap serta tidak mengalami perubahan maka metode pengambangan yang diterapkan kurang baik (Subiantoro \& Sardiarinto, 2018).

Pegawai yang ditugaskan diluar perusahaan salah satunya bagian marketing yang bertugas untuk memasarkan produk atau barang langsung kepada konsumen sampai terjadinya proses penjualan hingga transaksi penjualan berakhir. Peran pegawai bagi perusahaan sangatlah penting, maka kinerja pegawai harus diperhatikan seperti efisiensi akan kehadiran pegawai (Utami, 2018). Disiplin kerja merupakan sikap yang sangat diperlukan oleh setiap orang dalam usaha untuk meningkatkan kinerja guna mencapai tujuan perusahaan. Sehingga pegawai yang berkerja langsung diluar perusahaan dituntut untuk menunjukkan kinerja yang baik dengan cara meningkatkan disiplin kerja dalam kehadiran pegawai. Menjadikan pegawai berkerja dengan baik dalam menyelesaikan tugas-tugasnya. (Lasmaya, 2016).

Sistem informasi absensi merupakan suatu pendekatan strategis terhadap peningkatan kinerja suatu perusahaan. Absensi pegawai dapat dicatat, diolah dan dipresentasikan didalam suatu sistem informasi absensi. Sehingga perusahaan memerlukan sistem absensi yang efektif untuk memudahkan perusahaan dalam mengatur kehadiran pegawai berdasarkan kewajiban, larangan dan sanksi apabila seorang pegawai melanggar atau tidak mentaati kewajibannya (Ekasari \& Diana, 2018). Banyak perusahaan yang menggunakan sistem absensi metode tradisional seperti mesin ceklok, fingerprint atau menggunakan media kertas yang memiliki berbagai keterbatasan dan kelemahan seperti membuat seorang pegawai yang ditugaskan diluar perusahaan harus datang ke kantor terlebih dahulu untuk melakukan absensi. Hal ini memungkinkan seorang pegawai tidak melakukan absensi dikarnakan memerlukan waktu lebih dalam melakukan absensi ke kantor. Hal tersebut akan berdampak pada perusahaan dalam kinerja pegawai untuk menjalankan tugastugasnya (Suwandi, 2016).

Terdapat beberapa penelitian terkait sebelumnya mengenai sistem absensi. Pengembangan sistem absensi ini melakukan dua tinjauan pustaka terhadap penelitian sebelumnya untuk menjadi tolak ukur dalam pengembangan sistem ini. Sistem Informasi Absensi Pegawai Menggunakan Metode RAD dan Metode LBS Pada Koordinat Absensi (Sikumbang et al., 2020). Penelitin ini menjelaskan prihal Badan Pusat Statistik yang berada di Kota Bandung sudah menerapkan teknologi sistem absensi menggunakan teknologi fingerprint. Adapun permasalahan yang terjadi yaitu saat pegawai ditugaskan untuk melakukan perjalanan dinas sering kali pegawai tersebut tidak melakukan absensi terlebih dahulu ke kantor. Penelitian selanjutnya mengenai Implementasi Geolocation Absen Kehadiran Dosen Politeknik Sriwijaya (Studi Kasus Dosen Jurusan Manajemen Informatika) Berbasis Android (Mesra et al., 2018). Penelitian ini mejelaskan tentang pemanfaatan geolocation dalam membantu proses absensi dosen pada Politeknik Negeri Sriwijaya sebagai sistem yang mendukung penentuan posisi dosen yang akan melakukan proses absensi.

Berdasarkan penelitian sebelumnya mengenai sistem absensi dalam membuat laporan rekapan kehadiran, belum ada penelitian yang secara khusus membahas mengenai perancangan sistem absensi menggunakan foto selfie dan geotagging untuk pegawai yang melakukan tugas diluar perusahaan. Proses absensi menggunakan fitur selfie dapat mengurangi pegawai dalam melakukan kecurangan dan memudahkan pegawai dalam melakukan abesnsi sehingga perusahaan dapat melihat lokasi atau posisi pegawai (Pratama et al., 2019). Dengan memanfaatkan fitur geotagging sebagai penyampaian informasi dalam bentuk sebuah foto sehingga dapat digunakan sebagai tempat berbagi lokasi letak yang nantinya dapat mengetahui lokasi pegawai ditugaskan pada saat proses pengambilan foto. Geotagging adalah sebuah proses penambahan informasi posisi data pada GPS berupa informasi latitude dan longitude dalam sebuah foto digital (Defitria et al., 2018). Titik lokasi keberadaan pegawai akan digunakan untuk melakukan absensi sehingga perusahaan mengetahui lokasi yang dilakukan oleh pegawai dalam proses absensi (Nurikawati \& Rachmat, 2016).

Berdasarkan masalah pada penelitian ini, diperlukan suatu sistem informasi absensi yang memungkinkan untuk meminimalisir terjadinya kendala dalam proses absensi pegawai yang bertugas diluar. 


\section{Metode Penelitian}

Pada penelitian ini dilakukan beberapa tahap penelitian. Adapun beberapa tahapan penelitian yang dibuat dengan kerangka penelitian seperti Gambar 1.

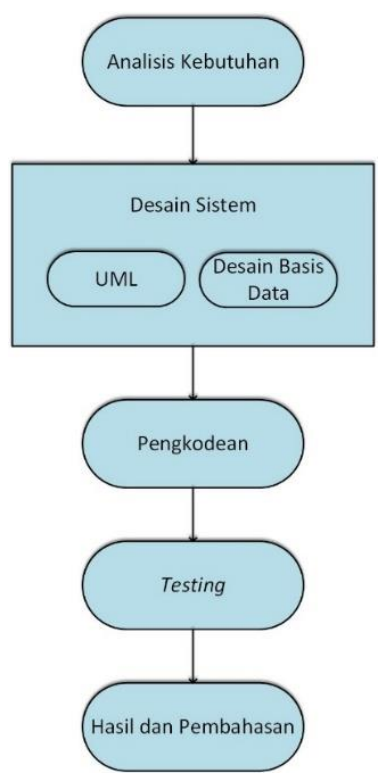

Gambar 1. Kerangka Penelitian

\subsection{Analisis kebutuhan}

Sebelum melakukan tahap pengembangan sistem informasi, peneliti melakukan proses analisis kebutuhan berupa studi literatur. Pada tahap ini peneliti mencari teori-teori terkait yang relevan terhadap permasalahan yang didapatkan. Referensi ini dapat di cari dari buku, jurnal, artikel ataupun laporan penelitian yang lain. Tujuan dari studi literatur ini yaitu untuk memperkuat permasalahan yang didapat serta sebagai dasar teori dalam melakukan penelitian.

Adapun tahap analisis kebutuhan dilakukan dengan maksud untuk merancang alur sistem dan data apa saja yang dapat digunakan dalam sistem. Serta menentukan kebutuhan apa saja yang akan digunakan pada saat perancangan sistem informasi absensi menggunakan foto selfie dan geotagging.

\subsection{Desain sistem}

Pada desain sistem yang dilakukan, peneliti menggunakan 2 desain sistem yang dilakukan yaitu:
A. UML (Unified Modelling Language)

Pada tahap uml peneliti akan membuat alur sistem berjalan serta hubungan user dengan sistem. Adapun uml yang digunakan yaitu:

1. Use case diagram

Use case diagram digunakan untuk merancang sistem yang akan di buat, use case diagram dapat digunakan untuk melihat kegiatan yang ada pada user serta siapa saja yang berhak menggunakan sistem tersebut. Pada perancangan sistem yang akan digunakan, penggunaan sistem hanya dapat diakses oleh pengguna saja.

2. Activity diagram

Activity diagram digunakan untuk menunjukkan seluruh aktivitas atau kegiatan dari sistem, dimulai dari proses, keputusan yang terjadi hingga berakhirnya kegiatan pada sistem.

3. Sequence diagram

Sequence diagram menggambarkan aktivitas dari suatu objek pada use case dengan menjelaskan kegiatankegiatan objek dan pesan yang akan dikirimkan dan diterima oleh objek.

4. Class diagram

Class diagram menjelaskan seluruh class yang terlibat dalam perancangan serta mengetahui hubungan antar class secara logic. Maka akan dibuat sebuah rancangan class diagram agar relasi antara rancangan class dengan erd dapat terbentuk dengan baik.

\section{B. Desain basis data}

Pada desain basis data yang akan di rancang maka data-data yang digunakan pada sistem informasi dapat dibuat. Berikut merupakan desain yang digunakan dalam merancang basis data :

1. ERD (Entity Relationship Diagram)

Erd digunakan dalam merancang basis data, dengan menggunakan object dasar yang sering disebut dengan entitas dan hubungan (relation) antar object-object tersebut.

2. LRS (Logical Record Structure)

Pada tahap desain basis data menggunakan Irs akan merepresentasi dari struktur recordrecord yang terdapat pada tabel-tabel 
yang terbentuk dari hasil antar himpunan entitas

\subsection{Pengkodean}

Setelah tahap analisis sistem dan desain sistem dibuat untuk memenuhi kebutuhan dalam perancangan sistem informasi. Selanjutnya yaitu pembuatan program dari sistem informasi absensi menggunakan foto selfie dan geotagging berbasis android. Sistem ini hanya dapat diakses oleh user pengguna. Dengan alur yang telah dibuat sebelumnya serta basis data yang telah ditentukan.

\section{A. Perangkat lunak}

Perangkat lunak atau software merupakan rangkaian intruksi yang tersusun secara teratur sehingga komputer dapat bekerja untuk mengolah suatu data dan mendapatkan informasi yang dibutuhkan oleh user. Perangkat lunak (software) yang digunakan dalam pembuatan sistem ini yaitu:

1. Sistem operasi windows 7 ultimate.

2. Android studio versi 3.6.3.

3. Xampp untuk local internet dan penyimpanan database.

4. Chrome sebagai browser.

\section{B. Perangkat keras}

Adapun perangkat keras yang digunakan dalam menjalankan software ataupun program aplikasi yang akan digunakan. Perangkat keras sangat dibutuhkan agar hasil kinerja dari sistem komputer dapat berjalan dengan maksimal hingga dapat dirasakan oleh user. Perangkat keras yang digunakan dalam proses komputerisasi, diantaranya:

1. Api 21: android os versi 5.0 (Iollipop).

2. Ram minimal $1 \mathrm{gb}$.

3. Kamera minimal $5 \mathrm{mp}$.

4. Gps.

\subsection{Testing}

Pada tahap sebelumnya telah dibuat analisis sistem, desain sistem dan pengkodean selanjutnya adalah pengujian. Tahap pengujian ini dilakukan dengan pengujian blackbox, pengujian ini berfokus pada pengujian kesesuaian alur fungsi pada aplikasi. Langkah dalam pengujiannya yaitu dengan membuat test case untuk menguji fungsi-fungsi yang ada pada aplikasi, dan membuat test case untuk menguji kesesuaian alur kerja suatu fungsi di aplikasi dengan requirement yang dibutuhkan oleh pengguna serta mencari bugs atau eror dari tampilan aplikasi.

\section{Hasil dan Pembahasan}

\subsection{Analisis Kebutuhan}

Pada pembahasan ini peneliti melakukan studi literatur untuk mendukung proses pembuatan sistem yang baru. Hasil studi literatur yang dilakukan peneliti yaitu terjadinya kendala pegawai dalam waktu dan jarak tempuh yang lebih untuk melakukan absensi saat ditugaskan diluar perusahaan dan kesulitan perusahaan dalam memonitoring pegawainya yang ditugaaskan diluar perusahaan. Pelaku penggunaan sistem terdiri atas administrator dan user sebagai pengguna. Admin merupakan pihak administrator yang dapat mengakses seluruh data pada sistem. Pegawai sebagai user pengguna sistem yang hanya dapat mengakses absensi masuk dan absensi keluar serta rekapitulasi absensi. Setelah melakukan analisis terhadap permasalahan yang ada maka dibuatlah sistem untuk membantu, mempermudah serta mempersingkat waktu.

\subsection{Implementasi}

Tujuan implementasi ini yaitu untuk memberikan panduan aplikasi sistem absesnsi serta penjelasan teknis untuk pegawai atau user yang menggunakan aplikasi absensi ini. Implementasi yang dimaksud untuk membantu pegawai dalam melakukan absensi diluar perusahaan secara online.

1. Tampilan Login

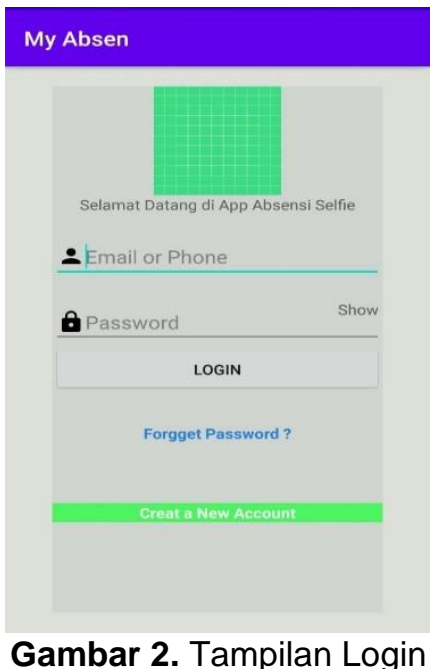

Gambar 2. Tampilan Login 


\section{Tampilan Halaman Utama}

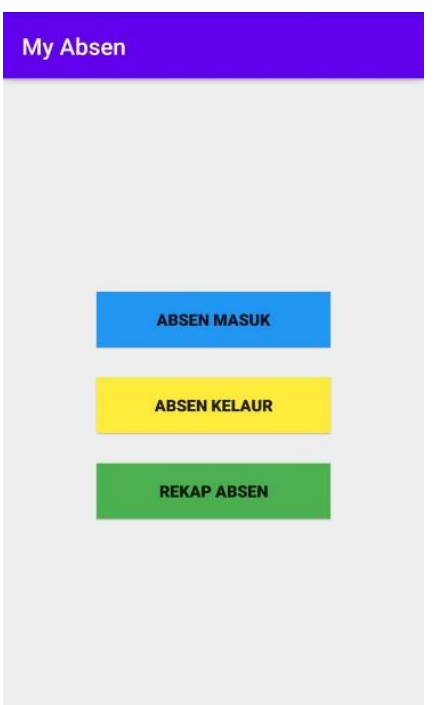

Gambar 3. Tampilan Halaman Utama

Hasil dari penelitian ini merupakan sistem informasi absensi menggunakan foto selfie dan geotagging berbasis android yang dapat digunakan oleh 2 akses yaitu administrator dalam pengelolaan data serta user pengguna yaitu pegawai yang ditugaskan diluar perusahaan. Sistem informasi ini dikembangkan untuk mempermudah pegawai dalam melakukan absensi diluar perusahaan. Dengan dibuatnya aplikasi ini menjadikan pegawain lebih efektif dan efisien dalam melakukan absensi dibandingkan harus datang ke kantor terlabih dahulu untuk melakukan absensi serta memudahkan perusahaan dalam memonitoring pegawainya yang ditugaskan diluar perusahaan.

\section{Kesimpulan}

Perancangan sistem informasi absensi menggunakan foto selfie dan geotagging merupakan pengembangan sistem dari penelitian-penelitian yang sebelumnya. Dari berbagai penelitian sebelumnya peneliti melakukan pembaruan yang diharapkan dapat membantu dan mempermudah dalam absensi sehingga menjadikannya lebih efektif dan efisien.

Berdasarkan dari penjelasan yang telah di jelaskan pada bab-bab sebelumnya, penulis dapat mengambil kesimpulan seebagai berikut:

1. Pembuatan sistem informasi absensi ini dapat mempermudah pegawai dalam melakukan absensi sehingga tidak perlu pegawai datang ke kantor untuk melakukan absensi yang memakan waktu dan jarak tempuh.

2. Dengan adanya sistem ini perusahaan dapat memonitoring pegawinya yang bertugas diluar perusahaaan.

\section{Saran}

Dari kesimpulan yang penulis kemukakan diatas, maka peneliti mencoba memberikan beberapa saran kepada peneliti selanjutnya yang mungkin dapat menjadi referensi untuk peneliti selanjutnya. Adapun saran dari penulis yaitu sebagai berikut:

1. Pada penelitian selanjutnya, dapat melakukan pengembangan sistem absensi berbasis android menjadi berbasis IOS.

2. Dalam pengembangan sistem selanjutnya untuk menambahkan fitur keamanan yang lebih untuk mengurangi adanya kecurangan saat absensi dan manipulasi data.

3. Untuk memudahkan user pengguna, maka disarankan untuk penelitian selanjutnya memperbaiki desain interface pada aplikasi sehingga terlihat lebih menarik.

\section{Referensi}

Defitria, U., Priyambadha, B., \& Rusdianto, D. S. (2018). Pembangunan Aplikasi Social Geotagging Destinasi Wisata Berbasis Android. Journal Pengembangan Teknologi Informasi Dan IImu Komputer, 2(12), 6610-6617.

Ekasari, M. H., \& Diana, D. (2018). Aplikasi Absensi Mahasiswa dan Dosen STMIK Jakarta STI \& $\mathrm{K}$ Berbasis Web Menggunakan PHP dan MySQL. Jurnal IImiah Komputasi, 17(2), 109-117.

Lasmaya, S. M. (2016). Pengaruh Sistem Informasi SDM Kompetensi Dan Disiplin Kerja Terhadap Kinerja Karyawan. Journal Ekonomi, Bisnis \& Entrepreneurship, 10(1), 25-43.

Mesra, R., Rusdyanto, D., \& Meiriska, I. (2018)

IMPLEMENTASI

GEOLOCATION ABSEN KEHADIRAN DOSEN POLITEKNIK SRIWIJAYA ( STUDI KASUS DOSEN JURUSAN MANAJEMEN INFORMATIKA BERBASIS.

http://eprints.polsri.ac.id/id/eprint/5765

Nurikawati, R., \& Rachmat, A. (2016). Rancang Bangun Aplikasi Absensi 
Pegawai Berbasis Web (Studi Kasus Kantor Sekertariat Daerah Majalengka). Jurnal Program Studi Informatika,Fakultas Teknik, Universitas Majalengka, 248-254.

Pratama, Y., Istoningtyas, M., \& Rasywir, E. (2019). Sistem Pelaporan Kinerja Sales Dan Marketing Dengan Fitur Absensi Berbasis GIS Pada Platform Android. Seminar Nasional Sains \& Teknologi Informasi (SENSASI), 691-696.

Sikumbang, M. A. R., Habibi, R., \& Pane, S. F. (2020). Sistem Informasi Absensi Pegawai Menggunakan Metode RAD dan Metode LBS Pada Koordinat Absensi. JURNAL MEDIA INFORMATIKA BUDIDARMA, 4(1), 59-64.

https://doi.org/10.30865/mib.v4i1.1445

Subiantoro, \& Sardiarinto. (2018). PERANCANGAN SISTEM ABSENSI PEGAWAI BERBASIS WEB Studi Kasus: Kantor Kecamatan Purwodadi. JURNAL SWABUMI, 6(2), 184-189.

Suwandi, A. P. (2016). Sistem Informasi Pemantauan Kinerja Sales Memanfaatkan Monitoring Geofencing dan Teknologi Cloud Message Berbasis Mobile. JOURNAL OF INFORMATION AND TECHNOLOGY, 4(1), 129-134.

Utami, D. R. (2018). PERAN SALES DALAM AKTIVITAS PEMASARAN PADA HOTEL ASTON INN MATARAM.

Wardhani, N. K., \& Aziz, M. T. A. (2018). Sistem Informasi Manajemen Sumber Daya Manusia Berbasis Web ( Studi Kasus: Pt . Klik Teknologi Indonesia ). Jurnal TECHNO Nusa Mandiri, 15(2), 145-152.

https://ejournal.nusamandiri.ac.id/index .php/techno/article/view/24 